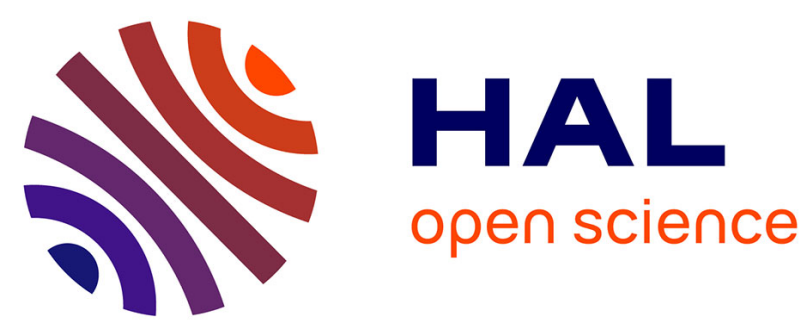

\title{
Operators and criteria for integrating FEA in the design workflow: Toward a multi-resolution mechanical model
}

\author{
Jean-Claude Léon, Philippe Maurice Marin, Gilles Foucault
}

\section{To cite this version:}

Jean-Claude Léon, Philippe Maurice Marin, Gilles Foucault. Operators and criteria for integrating FEA in the design workflow: Toward a multi-resolution mechanical model. A. Di Bucchianico; R. Mattheij; M. Peletier. Progress in Industrial Mathematics at ECMI 2004, 8, Springer, pp.616-620, 2006, Mathematics in industry, 10.1007/3-540-28073-1_94. hal-00401211

\section{HAL Id: hal-00401211 \\ https://hal.science/hal-00401211}

Submitted on 2 Jul 2021

HAL is a multi-disciplinary open access archive for the deposit and dissemination of scientific research documents, whether they are published or not. The documents may come from teaching and research institutions in France or abroad, or from public or private research centers.
L'archive ouverte pluridisciplinaire HAL, est destinée au dépôt et à la diffusion de documents scientifiques de niveau recherche, publiés ou non, émanant des établissements d'enseignement et de recherche français ou étrangers, des laboratoires publics ou privés. 


\title{
Operators and Criteria for Integrating FEA in the Design Workflow: Toward a Multi-Resolution Mechanical Model
}

\author{
J.-C. Léon ${ }^{1}$, P.M. Marin ${ }^{2}$, and G. Foucault ${ }^{3}$ \\ Laboratoire Sols, Solides, Structures, INPG - UJF - UMR CNRS 5521, Domaine \\ Universitaire BP 53, 38041 Grenoble Cedex 9, France \\ 1 jean-claude.leon@hmg.inpg.fr \\ 2 philippe.marin2@hmg.inpg.fr \\ 3 gilles.foucault.1@ens.etsmtl.ca
}

Summary. In the design workflow, CAD models of complex components include more and more details. A transformation of such models into Finite Element (F.E.) models often generates a much too large number of elements to be used directly. Generally, the removal of shape details or idealization operations are required to prepare F.E. models. These modifications must preserve the analysis result and the user must control the process in order to ensure sufficient accuracy of the F.E. results. In accordance to the analysis problems, the simplification process generates different appropriate F.E. models. In this paper, we present different operators and criteria to prepare analysis models from CAD models.

Key words: shape simplification, mesh, polyhedral model, mechanical criterion, finite element accuracy

\section{Introduction}

Design models are used by all the actors of the design process and therefore contain numerous details. These models are often too refined for mechanical analyses and their direct use would generate too many finite elements. The adaptation of the model shape needs the removal of its details when their presence has either no or limited effects on its mechanical behavior while requiring an important local mesh density. Examples of these details include fillets, but also detailed entities such as holes, small blocks, etc.

Various software make it possible to automate this step partially. Several categories of approaches have been proposed to solve the problems involved by the preparation of F.E. models from CAD data. A first one addresses configurations were small features must be removed to get the geometric model more compatible with the size of the F.E. required $[7,2,5]$. These approaches 
are strongly dependent on the modelling history of the part and work on the construction tree of the object and the removal of user-selected features. A second one starts with a polyhedral model of the part $[8,1,3]$. In order to simplify the model, different adaptation functions work on the initial polyhedral model. They combine decimation process and removal of topological details. Another category of approaches is characterized by idealization treatments. Such operations are often required to transform a volume into an open surface to model a plate behaviour. Similar operations hold for transforming a volume feature into a line to model a beam behaviour of the structure.

The accuracy of F.E. computations is one of the main concerns of the users. The sources of the errors are multiple, errors of discretization, uncertainty about the boundary conditions and the behaviour law of the constitutive material, simplification of the shape, ... The quality of F.E. computation can be strongly influenced by the simplifications carried out on the shape. Appropriately choosing and monitoring these simplifications is therefore of primary importance. When the preparation of the model is manual, its quality depends on the engineer's know-how. For an automatic simplification process, the monitoring process uses geometrical criteria, curve, size [9]... In a priori step, geometrical criteria related to the mechanical properties of the problem can be added, variation of mass, volume, sections, centre of inertia [4]... A posteriori indicators can be used also and adaptive simplification process can be performed to define the most suited simplified model for each analysis case.

Section 2 presents the existing polyhedral model simplification algorithms we use to automatically prepare F.E. models. In section 3, different implemented criteria are listed and some examples illustrate their efficiency.

\section{Simplification operators}

Our approach uses an intermediate polyhedral model of the object. Using such a representation, we can integrate data from CAD models, pre-existing F.E. meshes or 3D scans. algorithm.
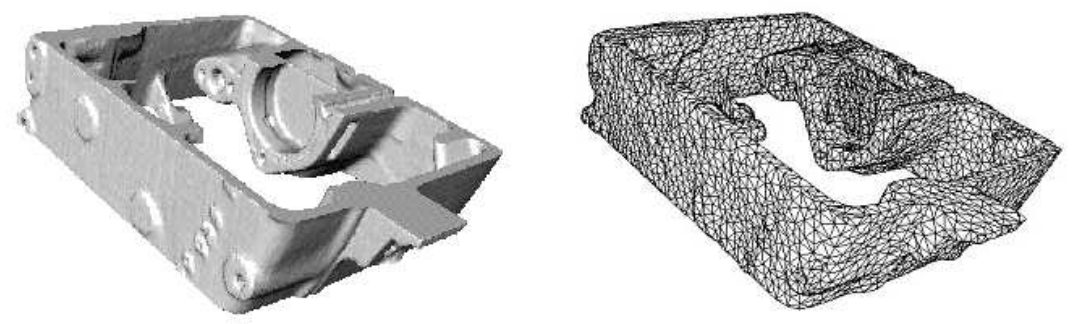

Fig. 1. Scan of a crankcase (courtesy Tomoadour-TurboMéca), generation of a F.E. mesh (total time $\sim 2 \mathrm{~h}$ ), 427132 faces in the initial model and 11924 in the F.E. mesh. 
The simplification process is based on an iterative vertex removal. Figure 1 shows the result of a simplification process.

\section{Mechanical criteria}

During a simplification process, a priori criteria are geometric ones but they can be related to mechanical property variations of mass, volume, section, centre of inertia. These indicators have been developed with our decimation process. We could provide the user either macro-scale information over the whole object or micro-scale information on the smallest possible entity of the geometrical model. Figure 2 shows two examples of such an indicator.
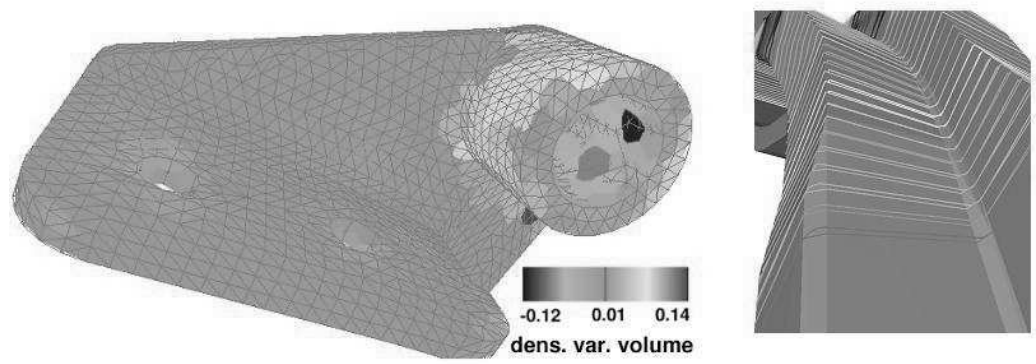

Fig. 2. Two examples of a priori criteria, variation of volume on the left part and variation of sections on the right part.

A priori criteria are an interesting information for the users but they cannot quantify directly the real influence of geometric simplifications on a F.E. simulation. For example, the errors generated by a hole removal will depend on the dimension of the hole but also of its location over the component. This form feature can be in an area involving either low or high stresses. To take into account its position, a mechanical criterion needs information about the highly stressed areas and hence a sketch of the F.E.A. results. To gain an idea of these results requires to set up an a posteriori process. After a simulation on the simplified part, mechanical criteria are computed for evaluate the influence of each suppressed feature. Based on criteria, the engineer can validate the quality of his (resp. her) F.E. results. These criteria can also used in an adaptive process of simplification to refine the simplified part by adding some of the suppressed features according to their mechanical influence.

Such a process of simplification was used in [10]. The criterion used was the error of discretization on the simplified problem and the map of sizes of an optimal mesh for this problem. The program removes details if the size of the detail is lower than that given in this area by the map of sizes. Another criterion can be estimation of the influence of each simplification on 
the strain energy variation [6]. In the framework of stationary linear problems, this variation is given by eq. (1) where $\sigma_{2}$ are the stresses of the simplified model, $U_{1}$ the displacements of the initial model and $n$ the outward unit normal. Obviously, these displacements are unknown and can be estimated by local computations around the removed feature.

$$
\int_{\text {feature boundary }} \sigma_{2} \cdot U_{1} \cdot n \cdot d s=\Delta \text { strain energy variation }
$$
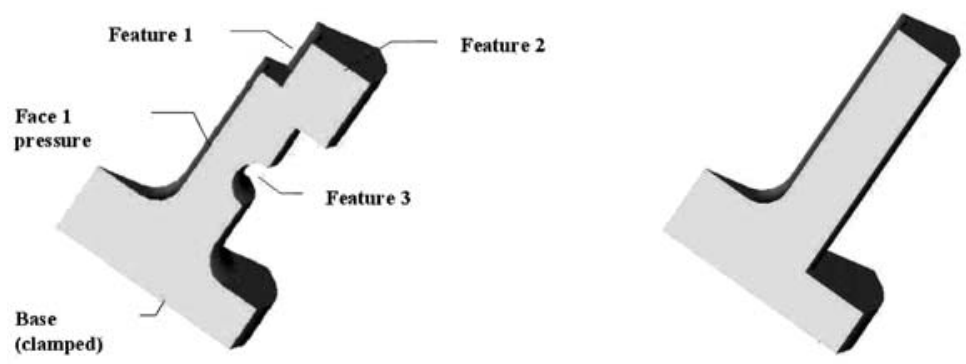

Fig. 3. Initial CAD model on the left and associated simplified model for analysis

On Fig. 3, we show an example of static problem that illustrates the efficiency of our criterion. The simplified model has been obtained by suppressing four features. In order to evaluate the efficiency of the criterion, we compute the solution and the strain energy on the initial part but also on the simplified one. We can see on table 1 that this criterion produces a good estimation of the influence of each simplification. During an adaptive process, the user computes the solution and the influence indicator on the simplified model. In this example, if the user wants to bound the accuracy to $1 \%$, the simplified model must be refined by adding features 3 and 4 .

Table 1. For each feature simplification, comparison between the real strain energy variation and our estimation of this variation.

\begin{tabular}{llll}
\hline & $\mathrm{A}=$ real variation & $\mathrm{B}=$ Influence indicator & efficiency $\mathrm{A} / \mathrm{B}$ \\
\hline feature 1 & $-0.014 \%$ & $-0.009 \%$ & $1.56 \%$ \\
feature 2 & $0.27 \%$ & $0.26 \%$ & $0.96 \%$ \\
feature 3 & $-8.4 \%$ & $-8.3 \%$ & $1.01 \%$ \\
feature 4 & $16 \%$ & $18 \%$ & $0.89 \%$ \\
\hline
\end{tabular}




\section{Conclusion}

The design process of complex structures needs the resolution of multiple mechanical analyses. Each analysis requires the generation of an adequate simulation model. To define easily such models and integrate F.E.A. in the design workflow, it is necessary to set up efficient simplification operators and criteria for evaluating and validating the simplification process. In this paper, we have presented a set of treatments contributing to this integration.

Developments are in progress to add other mechanical criteria, like a priori stiffness variation, a posteriori indicator for modal analysis, ... Work is also needed to automate the adaptive process using our a posteriori indicator.

All these treatments help transform CAD models from pure into multiresolution mechanical models efficient for mechanical simulation preparation.

Acknowledgement. Future developments will be conducted in the AIM@SHAPE NoE framework. This Network of Excellence involves fourteen research teams about Shapes and associated semantic and it is supported by the European Community.

\section{References}

1. J. Cohen, D. Manocha, A. Varshney, and G. Turk. Efficient model simplification with global error bounds. In 5th MSI Workshop on Computational Geometry, Stony Brook, USA, 1995.

2. P. Dabke, V. Prabhakar, and S. Sheppard. Using features to support finite element idealisation. Proc. of Int. ASME DETC, 1:183-193, 1994.

3. L. Fine, L. Remondini, and J-C. Léon. Automated generation of FEA models though idealization operators. Int. Journal of Numerical Methods in Engineering, 49:83-108, 2000.

4. G. Foucault, P. Marin, and J-C Léon. Mechanical criteria for the preparation of finite element models. In Proc. of 13th International Meshing Roundtable. Sandia National Laboratories, 2004.

5. V. Fran, cois and J-C. Cuillère. 3D automatic remeshing applied to model modification. Computer Aided Design, 33:377-388, 2000.

6. P. Marin. Influence of geometrical simplifications on the accuracy of finite element computation. In Proc. of 4 th International Conference on Engineering Computational technology, Lisboa, 2004.

7. A. V. Mobley, M. P. Caroll, and S. A. Canann. An object oriented approach to geometry defeaturing for Finite Element Meshing. In Proc. of 7th International Meshing Roundtable. Sandia National Laboratories, 1998.

8. W.J. Schroeder, J. A. Zarge, and W. E. Lorensen. Decimation of triangle meshes. In Computer Graphics SIGGRAPH'92, pages 65-70, 1992.

9. P. Véron and J-C. Léon. Static polyhedron simplification using error measurements. Computer Aided Design, 29:287-298, 1997.

10. P. Véron and J-C. Léon. Shape preserving polyhedral simplification with bounded error. Computers \& Graphics, 22:565-585, 1998. 